\title{
The Analysis of the Curtain Wall Installation Robot: Based on the Test in the Construction Site
}

\author{
S. N. Yu, C. H. Choi, S. Y. Lee, C. S. Han, K. Y. Lee and S. H. Lee
}

\begin{abstract}
Automation in construction is one of the important issues in the field of robotics, but is distinct from factory automation (FA). Because of variations in materials and management, the role of automation in construction is often limited. A curtain wall is a large, heavy breakable object and requires precision installation, making it a better candidate for automated installation. A curtain-wall installation robot was built and tested at a real construction site and results were analyzed to refine the new concept of curtain-wall installation automation.
\end{abstract}

Index Terms - Curtain-wall, Automation in Construction, Progress Management, Optimal Mechanic Design, TRIZ Method, Curtain-wall installation Robot, Construction Process Analysis

\section{INTRODUCTION}

$\mathrm{A}$ S buildings become larger and more complicated, automation in construction has become more important [1]. Skilled labor is difficult to obtain and, moreover, handling heavy construction materials is not easy and may be dangerous. Several researchers have worked in the field of construction automation, but the real-world requirements can make development difficult. Unlike in factory automation, construction often involves a wide variety of materials and operating environments. Because of this, and moreover because of the complexity of construction, automation systems have been used only in special cases [2].

\section{A. Curtain-wall Installation}

A curtain-wall is a wall that doesn't bear the load of the building (i.e. a non-load bearing wall). It may shorten the construction period and can prevent excessive design of overall

This work was supported in part by the SAMSUNG Co. E\&C Group (Department of Construction), Sungnam, Korea.

Seung-Nam Yu and Chong-Ho Choi are with the Department of Precision Mechanical Engineering, Hanyang University, Seoul, Korea (corresponding author to provide phone: 8231-400-4062; fax: 8231-406-6242; e-mail: winboy@nate.com, hoya1155@paran.com).

Seung-Yeol Lee is with the Department of Mechatronics Engineering, Hanyang University, Seoul, Korea (corresponding author to provide phone: 8231-400-4062; fax: 8231-406-6242; e-mail: suprasy@ paran.com).

Chang-Soo Han was with University of Texas at Austin, USA. He is now with the Department of Mechanical Engineering, Hanyang University, Seoul, Korea (corresponding author to provide phone: 8231-400-5247; fax: 8231-406-6242; e-mail: cshan@ hanyang.ac.kr).

Kye-Young Lee and Sang-Heon Lee are with the SAMSUNG Co. E\&C Group(Department of Construction), Sungnam, Korea (e-mail: Kyle@samsung.com, shlee31@samsung.com). building with lightweight feature. Fig. 1 shows the general curtain-wall.

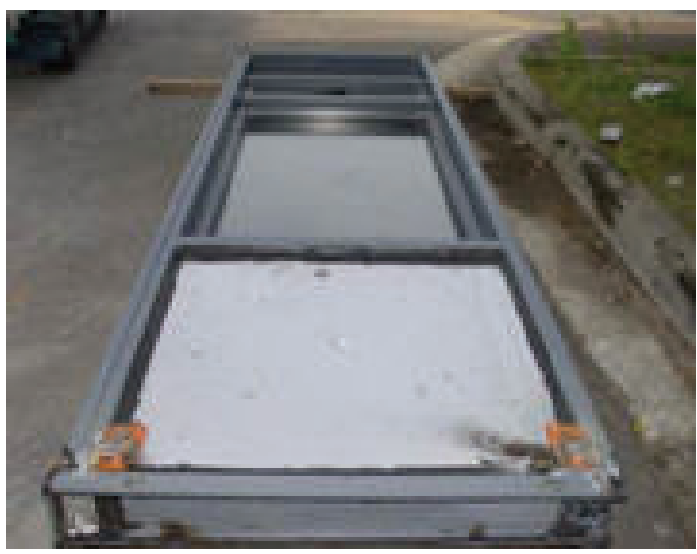

Fig. 1. Appearance of a curtain-wall

Using curtain-walls is a relatively recent innovation, and has several features worth observing. In the unit wall system, one of the methods of curtain-wall construction used in large-scale construction, aluminum, frames and glasses are assembled in the factory and delivered in units. The walls assembled are very large and heavy, and assembling them is very laborious in Fig. 2. The curtain-wall in the above image has a mass of about 400 $\mathrm{kg}$ a height over $4 \mathrm{~m}$.

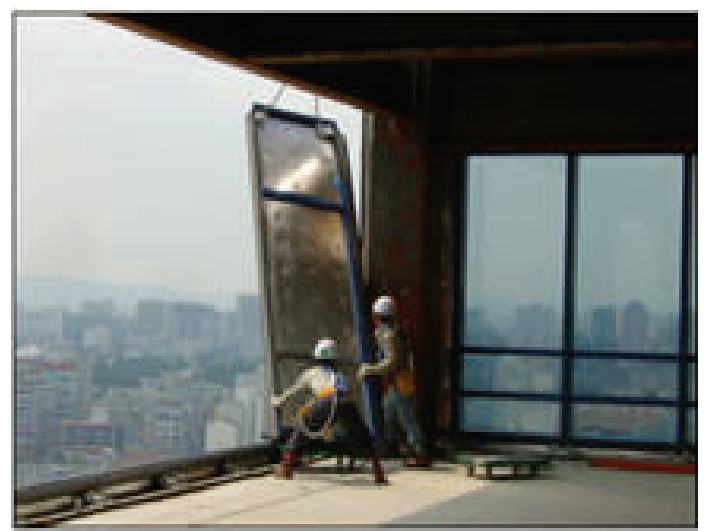

Fig. 2. Curtain-wall installation by human power

\section{B. Automation of Curtain-wall installation Process}

Because it uses homogeneous construction materials and is difficult to handle, curtain-wall installation is an ideal candidate for automation. A robot capable of automated 
assembly is shown in Fig. 3 [3]. In this paper, we discuss the design of the curtain-wall installation robot and the results of the on-site test. We also discuss the advantages and disadvantages of using the robot and how they might influence the design of the next model.

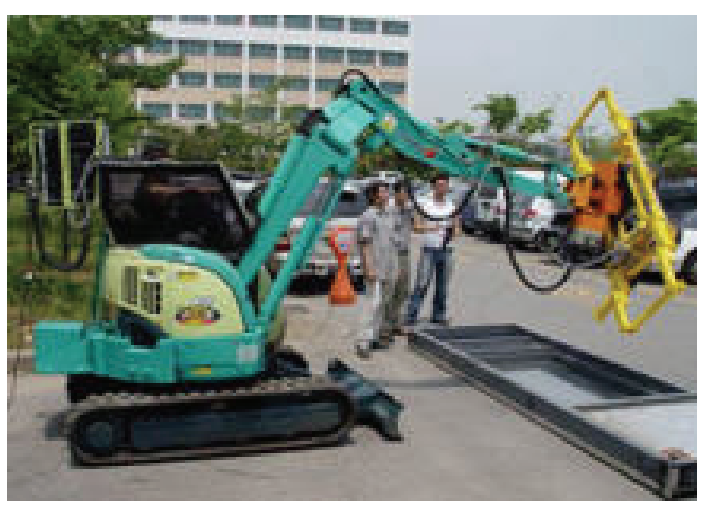

Fig. 3. Curtain-wall installation robot

\section{ANALysis of CURRENT PROCESS OF CURTAIN-WALL INSTALLATION}

Fig. 4. shows the structure of a curtain-wall and its auxiliary parts. The curtain-wall installation process has three possible types. For this study, we choose the 'UNIT type' and its process.

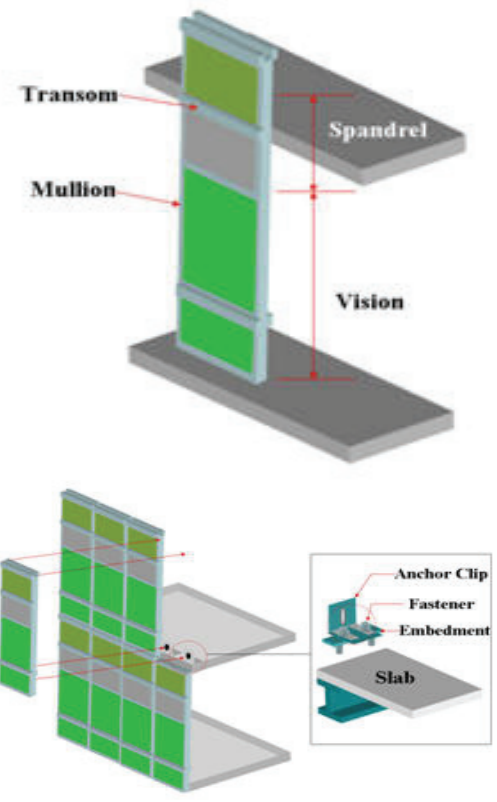

Fig. 4. 'UNIT' type curtain-wall

Fig. 5. describes the process of manual curtain wall installation ('UNIT' refers to the curtain-wall). The steps that we propose to automate are highlighted.

\section{A. Current Installation Process of Curtain-wall (by Human power)}

Fig. 6. illustrates the manual assembly process.

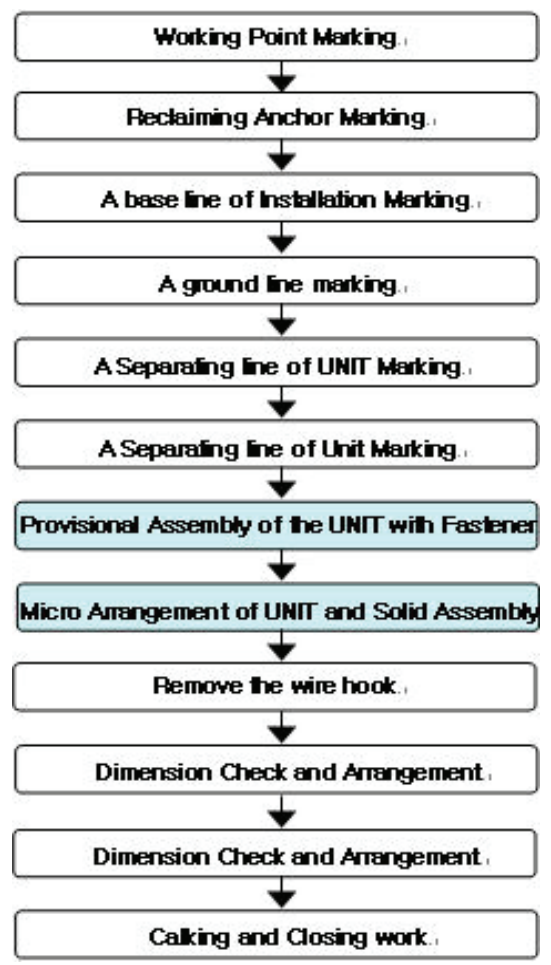

Fig. 5. General curtain-wall installation process

(1) The workers move the curtain-wall as close to the target position as possible.

(2) At the signal of the lower floor worker, the upper floor work operates the winch and lifts up the curtain-wall.

(3) Two workers (as shown in the picture) position the curtain-wall.

(4) The lower floor worker corrects the direction of the curtain-wall.

(5) The lower floor worker releases the winch slowly and puts down the curtain-wall.

(6) Arrange the wall precisely and Finish

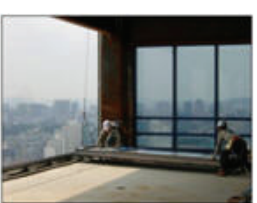

(1)

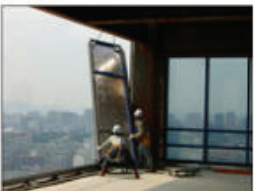

(3)

(5)

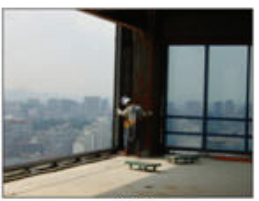

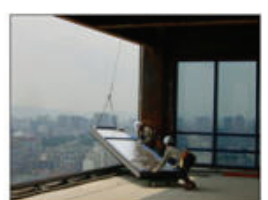

(2)

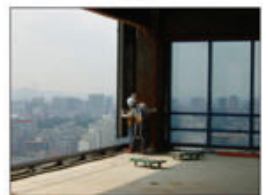

(4)

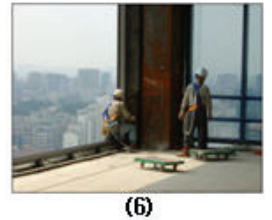

(6)
Fig. 6. The original curtain-wall installation process 


\section{B. Concept Design Development of a Curtain-wall Installation Robot}

When we design the system, we must consider four characteristics.

\section{(1) Performance}

We designed the maximum payload of the manipulator with regard to curtain-wall weight, and tested the elevation, assembly and safety capabilities of the total system.

\section{(2) Maneuverability}

We designed the 3-DOF end-effecter of this system to be operated by a teach pendant, and we tested its maneuverability. We gathered the data from the operators who participated in this test.

\section{(3) System Extensibility (Convenience)}

Each part of 3-DOF end effecters can be exchanged for other parts which have another other type of motion.

(4) Improve the efficiency of the total process
(4)

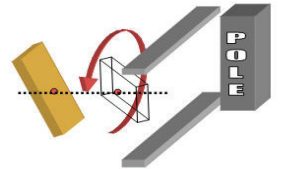

(5)
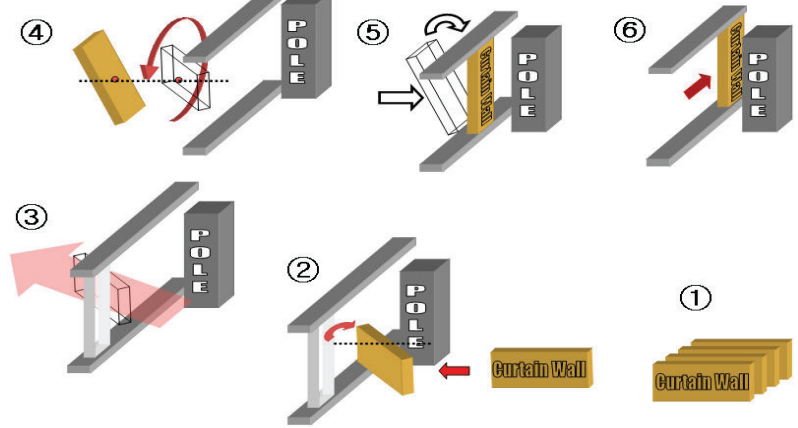

\section{(1)}

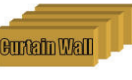

Fig. 7. Schematic of curtain-wall installation

To decide the DOF of the robot system, we analyzed the curtain-wall installation process in Fig. 7.

( $\square$ : End effecter motion, $\square$ : Boom motion)

(1) Select a curtain-wall.

(2) Pan the selected wall.

(3) Pass the wall through the slab.

(4) Rotate the wall.

(5) Robot move back, Assembly

6) Using micro move, complete the assembly.

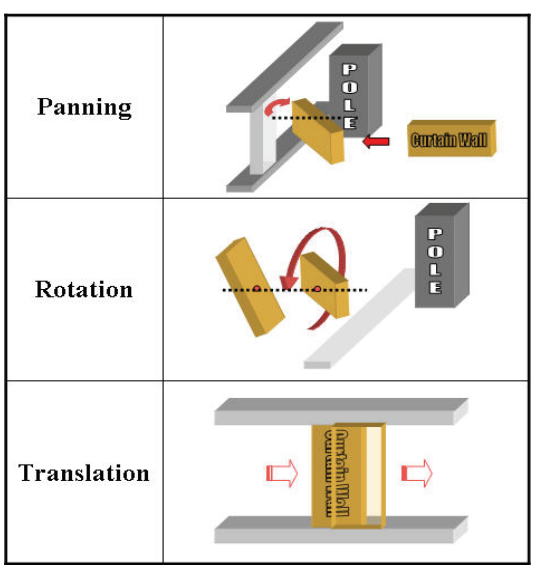

Fig. 8. DOF selection of robot system
Finally, we identified the 3-DOF modules for the end-effecter such as Fig. 8. We also considered the compactness of the hoist on the construction site and high DOF of the monition.

From an analysis of the installation process and economic considerations, we combine the general-purpose usage excavator and our 3-DOF manipulator. Fig. 9. shows the combination of the two systems.

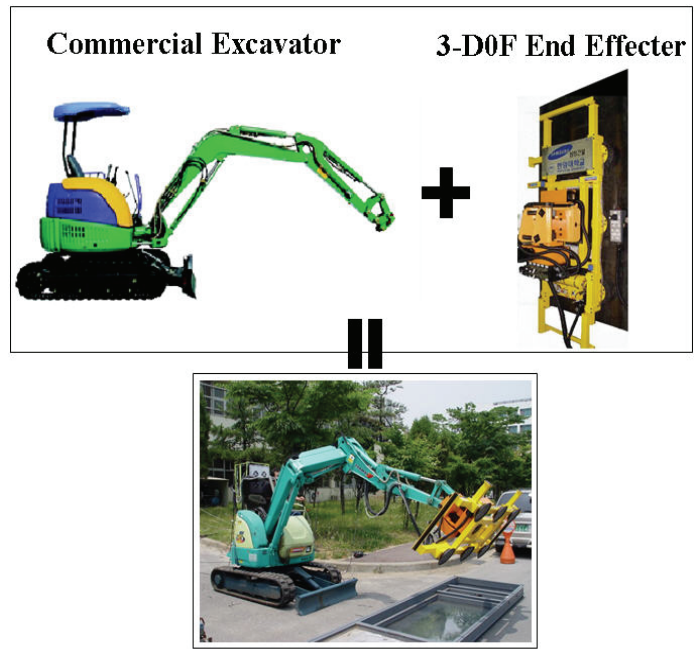

Fig. 9. Concept of curtain-wall installation robot

\section{Performance Test at a Real Construction Site}

We applied this system at a real construction site using curtain-wall building techniques. Fig. 10. shows the total process of curtain-wall installation using our automation system.
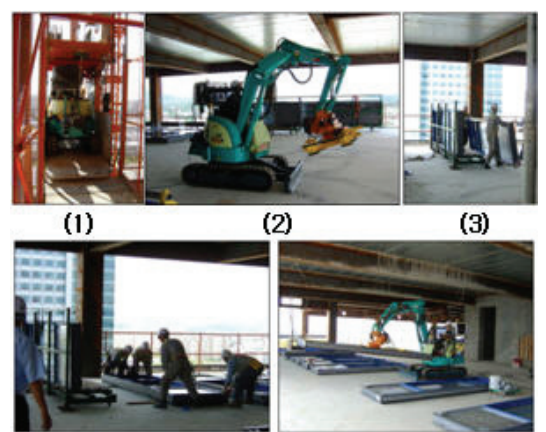

(4)

(5)

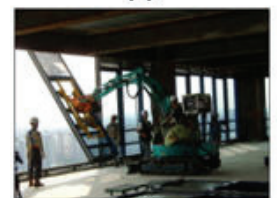

(6)

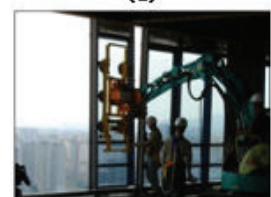

(8)

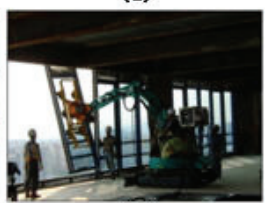

(7)

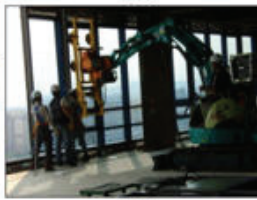

(9)
Fig. 10. Curtain-wall installation process using robot system 
(1) Position the machine using hoist.

(2) Set up parts.

(3) Select the curtain-wall.

(4) Place the wall near the target position.

(5) The robot picks up the curtain-wall.

(6) The robot approaches the target slab.

(7) With human guidance, the robot approaches the embedme -nt.

(8) Using 3-DOF end-effecter, move curtain-wall precisely.

(9) Release the vacuum pad and finish.

\section{TEST RESULT}

We estimated the system using 4 factors, Performance, System efficiency, Maneuverability and System Extensibility as shown before. First two factors of a system are analyzed in 'Test Results" and last two factors dealt in "Considerations."

\section{A. Assumption for Test}

Our test has several essential prerequisites. It dealt with below.

(1) To measure the task time, we set the starting point as shown in Fig. 11. (We do not consider curtain wall gripping time, because the pose and loading conditions of the curtain wall are different for each site.)

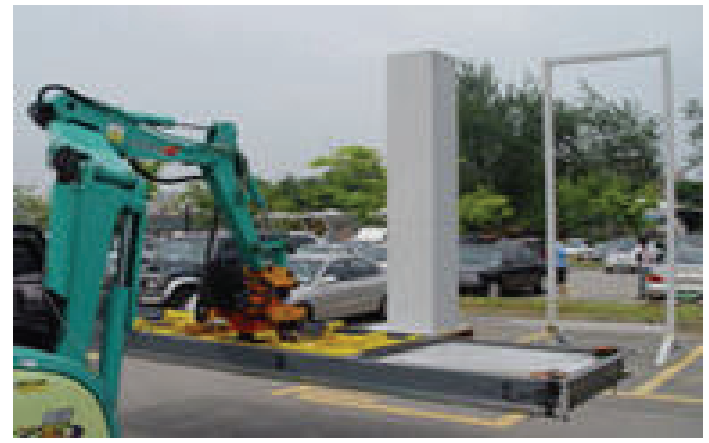

Fig. 11. Starting point for time measurement

(2) For the first test, we distribute 5 workers ( 3 on the lower flow and 2 on the upper) for safety. Originally, this system was designed for 3 workers ( 2 on the lower floor, one on the upper).

(3) Work space

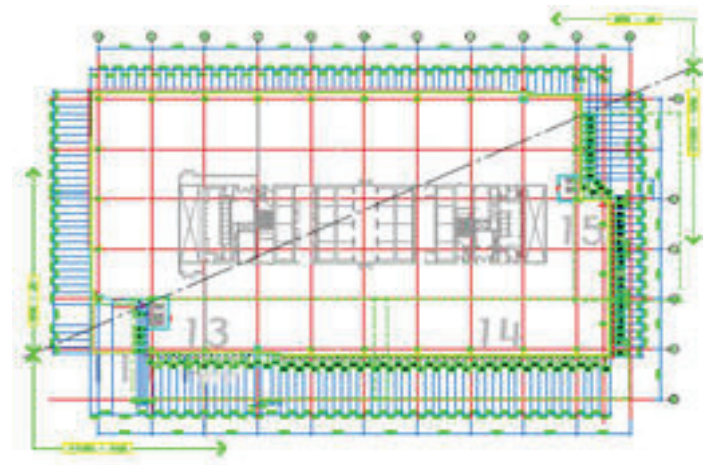

Fig. 12. Blueprint of test place

\section{B. Test Results}

(1) Performance

TABLE I shows the estimated and actual power required for each part. The installation task includes weighing the curtain wall and examining the performance of our system. Lifting during rotation is possible, but not optimal. So, when we applied this system to the real construction site, we fix a rule to constraint the starting pose as 'Rotating' to lift up the curtain-wall.

TABLE I

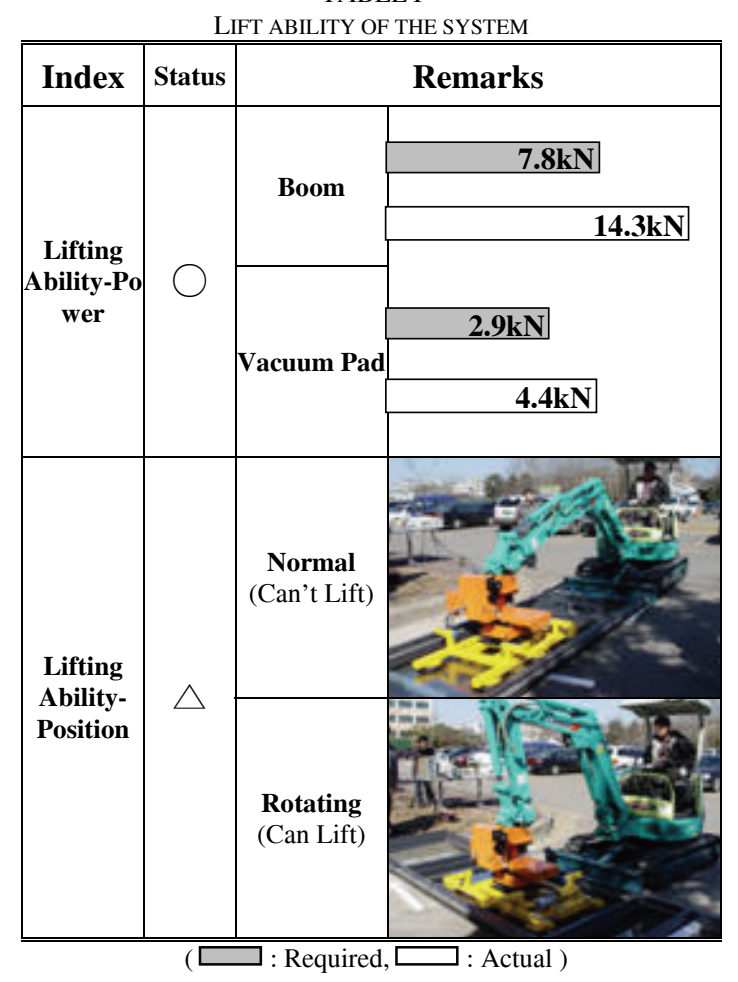

(2) Task Time

To compare human task with robot one, we measure the task time of curtain-wall installation process divide to 6 cases. TABLE II describes it.

TABLE II

TASK TIME $※ 1$

\begin{tabular}{|c|c|c|c|c|c|c|c|}
\hline \multirow{3}{*}{\multicolumn{2}{|c|}{ Task No. }} & \multicolumn{6}{|c|}{ Curtain-wall Type and Task Precedent } \\
\hline & & \multicolumn{2}{|c|}{ Wing not Attached } & \multicolumn{2}{|c|}{ Wing Attached } & \multicolumn{2}{|c|}{$\begin{array}{l}\text { Window for } \\
\text { Ventilation }\end{array}$} \\
\hline & & 1 & 2 & 3 & 4 & 5 & 6 \\
\hline \multicolumn{2}{|r|}{ Task Type } & $\begin{array}{c}\text { Hanging } \\
\text { Wire }\end{array}$ & $\begin{array}{c}\text { After } \\
\text { Hanging } \\
\text { Wire. }\end{array}$ & $\begin{array}{c}\text { Hanging } \\
\text { Wire }\end{array}$ & $\begin{array}{c}\text { After } \\
\text { Hanging } \\
\text { Wire }\end{array}$ & $\begin{array}{c}\text { Hanging } \\
\text { Wire }\end{array}$ & $\begin{array}{c}\text { After } \\
\text { Hanging } \\
\text { Wire }\end{array}$ \\
\hline \multirow{2}{*}{\begin{tabular}{|c|}
$\mathrm{H}$ \\
$\mathrm{U}$ \\
$\mathrm{M}$ \\
$\mathrm{A}$ \\
$\mathrm{N}$ \\
\end{tabular}} & $\begin{array}{c}\text { Normal } \\
\text { Installation }\end{array}$ & $2^{\prime} 11^{\prime \prime}$ & $59 "$ & $1^{\prime} 36^{\prime \prime}$ & $3^{\prime} 00^{\prime \prime}$ & 59 & $1^{\prime} 13^{\prime \prime}$ \\
\hline & $\begin{array}{l}\text { Install Behind } \\
\text { Column }\end{array}$ & $1^{\prime} 42^{\prime \prime}$ & $44 "$ & & & $1^{\prime} 7^{\prime \prime}$ & $4^{\prime} 50^{\prime \prime}$ \\
\hline \multirow{2}{*}{\begin{tabular}{|c|}
$\mathrm{R}$ \\
$\mathrm{O}$ \\
$\mathrm{B}$ \\
$\mathrm{O}$ \\
$\mathrm{T}$
\end{tabular}} & $\begin{array}{c}\text { Normal } \\
\text { Installation }\end{array}$ & $8^{\prime} 17^{\prime \prime}$ & $5^{\prime} 38^{\prime \prime}$ & & & & \\
\hline & $\begin{array}{l}\text { Install Behind } \\
\text { Column }\end{array}$ & $2^{\prime} 57^{\prime \prime}$ & $2^{\prime} 7^{\prime \prime}$ & & & & \\
\hline
\end{tabular}

(a) Task Time (All tasks completed by humans)

(b) Human vs. Robot (Normal Installation)

(c) Human vs. Robot (Behind Column) 
$※ 1$. The task number is given in Table 2 .

$※ 2$. In the above graph, the number in each label gives the task number; $\mathrm{H}$ and $\mathrm{R}$ denote human and robot tasks, respectively.

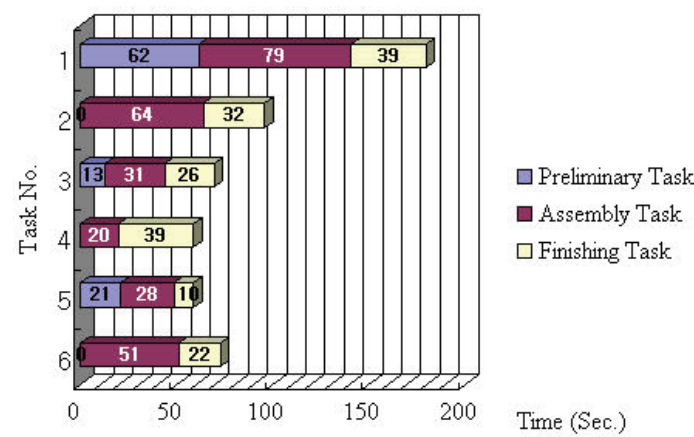

(a)

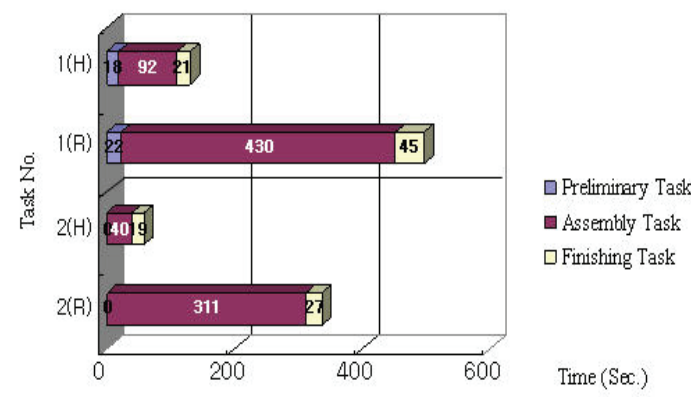

(b) 22

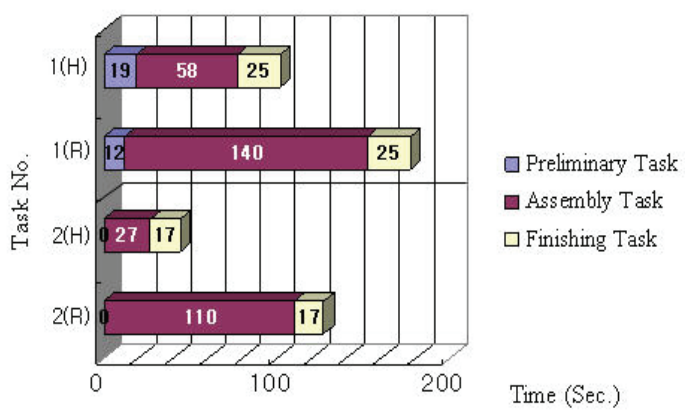

(c)

Fig. 13. Task time for curtain-wall installation

These results (Fig. 13.) are the task times of the curtain wall installation task. We measure the task time, dividing it into three parts. (a) The preliminary task includes the task of assembling the I-bolt at the curtain wall and hanging wire from a winch in the upper floor. If applicable, the wing should also be attached to the wall. (This wing is an attachment to put on a fair show.) (b) The assembly task time is the time it takes to assemble the curtain wall to the slot of the lower and next installed curtain wall. (c) The finishing task time is time it takes to fasten the curtain wall with the anchor clip using a fastener and to align the curtain wall. We repeat the test 3 times, and average the measured times.

As a result, a robot requires more time than a human for the task. In the case of normal installation, both the human and the robot spent most of their time on assembly but the robot has the linkage and dropping of the boom which requires more time.

\section{CONSIDERATIONS}

\section{A. Maneuverability}

To operate the assembly task using this system, two operators are needed. One man operates the booms and the excavator Cater filer; the other operates the 3-DOF manipulator. This is one of main reasons that robot-aided assembly is slower. When operators assemble the curtain-wall, the excavator operator and the manipulator operator communicate continuously. But, because construction sites are usually noisy, this type of communication is not always real-time. Fig. 14. describes it.

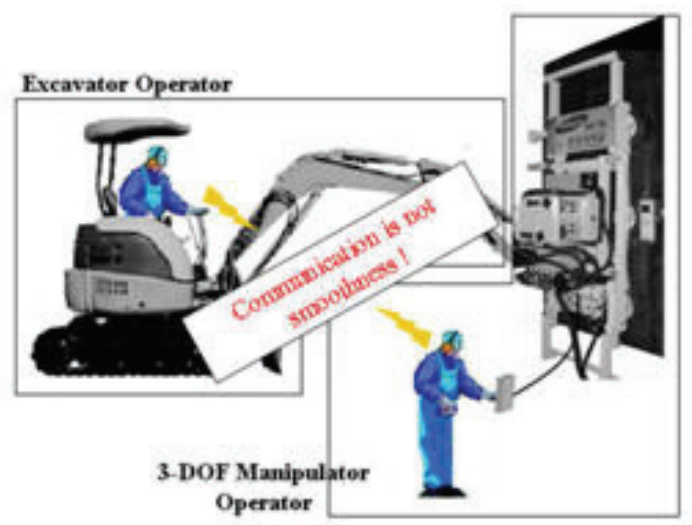

Fig. 14. It is difficult to communicate between the two systems.

\section{B. System Extensibility (Convenience)}

Such as Fig. 15.,We designed a 3-DOF manipulator but didn't consider the loading status of the curtain wall, so we couldn't use the end effecter to grip the loaded curtain wall directly. If we had considered it, we could use the 'tilting' module to grip the curtain wall. $\left(-65^{\circ} \sim 25^{\circ}\right.$ motion range is required considering the motion necessary for the assembly task only.)

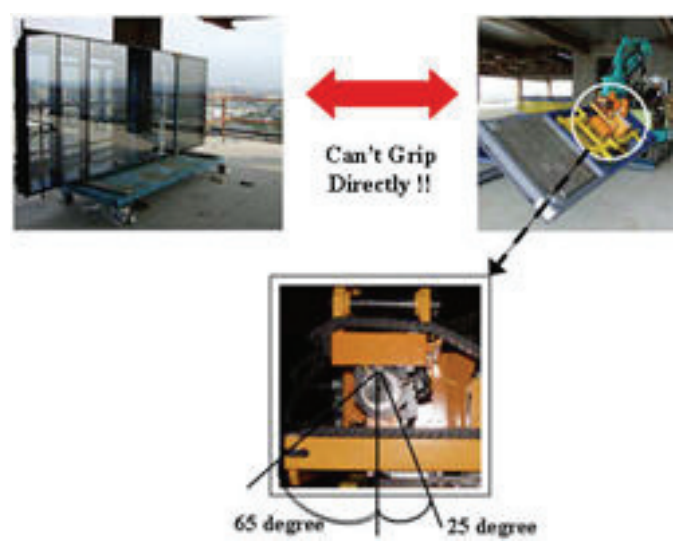

Fig. 15. Motion range of 3-DOF System

\section{Overall Criticism}

This system was supposed to automate curtain-wall installation. We constructed the system and tested the performance at a construction site, which proved instructive. 
First, using an excavator with a macro motion system is problematic. An excavator is not intended for that type of moving, and particularly of heavy material! That system has original linkage and drooping. Second, a 2-way control system by the excavator operator and 3-DOF manipulator is inefficient because the two workers must continuously communicate to assemble the curtain wall; ambient noise might make that communication difficult. Most importantly, the tasks of the two machines are not isolated, so two workers must operate the apparatus simultaneously.

This study offers an opportunity for new research into a man-machine cooperation system. Our upcoming research examines the integration of the two operators or exoskeleton-type human force amplification.

\section{REFERENCES}

[1] Albus, James S, "Trip Report: Japanese Progress in Robotics for Construction," International Journal of Robotics, Vol.2, No.2, pp.103 112, 1986

[2] Young-Suk Kim, Hyun-Chul Kim, Jung-Hoi Seo, Se-Wook Oh, “A Study for the Introduction of Construction Automation and Robotics Technologies and Domestic Construction Industry", Architectural Institution of Korea, Vol.17, No.2, pp. 111 120, 2001

[3] Seung-Yel Lee, Seung-Nam Yu, Hyeun-Seok Choi and Chang-Soo Han, "Multi-DOF Construction Robot for a Curtain Wall Installation of a Skyscraper", ISARC, pp.316 321, 2004

[4] B.Kahane, Y.Rosenfeld, "Balancing Human-and-Robot Integration in Building Tasks" Computer-Aided Civil and Infrastructure Engineering 2004, pp 393 410

[5] Kwan-Kyun Ko, Chang-Baek Son, "Efficiency Analysis of Lifting Equipment for construction of Apartments and Office Buildings", The Korean Construction Society 2001, pp 445 448

[6] Jin-u Lee, Chang-Baek Son, "An Analysis of Work Ratio for construction Curtain wall by Work Sampling Technique", The Korean Construction Society 2003, pp 519 522

[7] Jong-Bin Lee, Min-Rae Ro, Seong-Seok Go, "The Property of Building Construction Accident According to the Analysis of Building Accident Case", KOSHA 2004, pp 101-107 